\title{
Cash-Heavy to Cash-Lite Indian Society: A Case Study From the Rural Northern Indian State
}

\author{
NAVNEET DIMRI* and PRADEEP CHAUDHRY \\ Indian Institute of Forest Management, Nehru Nagar Bhopal, - 462003, India.
}

\begin{abstract}
The country needs to move away from cash-based transaction towards a cashless (electronic) payment system to help reduce currency management cost, track transactions, check tax avoidance, fraud etc., enhance financial inclusion and integrate the parallel economy with the mainstream. India has a majority percentage of the population residing in rural areas and by and large, the literacy percentage is low in spite of the adult education program launched by the government. Higher rural population, late adoption of technology by the country, lack of awareness among potential users, optimum utilisation of technology in hand, optimum marketing of e-delivery channels and security concern in use of e-delivery banking channels are some major issues causing hindrance in converting cash-rich Indian society to cash-lite one. The present article deals with these issues by way of presenting some key challenges noticed during a survey in rural areas of Uttar Pradesh state of India. We have suggested some ways to promote a cash-lite system among rural Indian society.
\end{abstract}

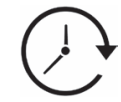

Article History

Received: 03 October 2018 Accepted: 30 December 2018

\section{Keywords}

Cashless,

Cash-lite,

Digital Economy,

Digital India,

Digital Transaction,

Digital Village.

\section{Introduction}

India has a majority percentage of population living in rural areas and still in large areas, the literacy percentage is low in spite of the adult education program launched by the government ${ }^{1}$. In the country's current context, the central government is talking about Cashless India, Digital India. As India is cash heavy society, we cannot make a cashless society overnight; it is impossible to remove all the physical money and to use digital money instead of physical currency. Of course, we can reduce the usage of cash and here the word "Cash-lite" comes. We want cash-lite society because the country is incurring $\$ 3.5$ billion in currency operation (currency management) a year. Each day 35.6 billion of the new currency was printed, and 32.7 billion retired ${ }^{2}$. In other words, India's love for cash costs $\$ 3.5$ billion a year for its currency operation (this includes printing

CONTACT Navneet Dimri $\$ navneet.iifm @ gmail.com 9 Indian Institute of Forest Management, Nehru Nagar Bhopal, - 462003, India. (c) (i)

(c) 2018 The Author(s). Published by Enviro Research Publishers.

This is an $\partial$ Open Access article licensed under a Creative Commons license: Attribution 4.0 International (CC-BY).

Doi: http://dx.doi.org/10.12944/CRJSSH.1.2.05 
of new currency, maintained of currency chest, ATM cost, \& etc.) from printing to disposal of the soiled bank note and investment in counterfeit note detector machine. This is a substantial additional cost on the country. For minimising it, we can reduce the usage of cash \& lessen the dependency on cash and start using digital mode of payments instead of cash.

With increasing digital technologies (i.e. micro ATM, ATM, White ATM, POS, mobile phone) in rural areas, there is a need for more effective financial inclusion approach which delivers sustainable services to the last mile customers in rural areas, especially women and lower socio-economic strata of the society. Also, it is increasingly clear that more focused attention is required in a decentralised manner to improve demand side capacities through sustained and customised financial literacy initiatives with localised content. To assess the situation in rural India, a research study was undertaken in the months of April-June 2018 to assess the situation at village level (in U.P. state) about digital literacy, usage of digital channels, key challenges in converting cash rich to the cash-lite system by the rural community.

\section{Methodology}

A mixed design approach method comprising of quantitative, qualitative and observation methods were used concerning the defined objectives. Focused Group Discussion (FGD) and In-Depth Interview (IDI) techniques were used as a qualitative research tool, and the structured questionnaire at the individual household level was used as a quantitative tool. The target group, research tool and methodology is depicted in Table 1 below.

Table 1: Meta-analysis table

\begin{tabular}{llll}
\hline $\begin{array}{l}\text { Target group } \\
\text { covered }\end{array}$ & Description & Research Instruments & Research Design \\
\hline Households & $\begin{array}{l}\text { Gender mix (male } \\
\text { \& female) } \\
\text { The BC agents appointed } \\
\text { by banks to promote and } \\
\text { manage financial services } \\
\text { operator }\end{array}$ & FGD & Questionnaire \\
$\begin{array}{l}\text { using micro-ATM } \\
\text { All Shopkeeper where POS } \\
\text { devices are deployed \& } \\
\begin{array}{l}\text { other local business } \\
\text { enterprises }\end{array}\end{array}$ & $\begin{array}{l}\text { In-depth-Interview } \\
\text { not deployed }\end{array}$ & Qualitative \\
\hline
\end{tabular}

Ten villages in Hasanganj block of Unnao district, Uttar Pradesh were selected for the study. An overall number of villages in Hasanganj block is 156 out of which customer service point (CSP) is available in 22 villages, and one of the criteria of selecting village was the availability of CSP (bank Mitra/bank Sakhi) which is deployed by the Grameen Bank of Aryavart. The first author surveyed total ten villages during his summer internship project (April 2018 to June 2018) where CSPs were available. The villages were selected by 4 clusters, and within a cluster, the village was selected randomly. Total no of sampling unit was 113, out of which 13 people/respondents don't respond to the questionnaire. Therefore effective no of sample size was 100 individuals comprising age group from 18 to 80 . The selection of individuals was made via snowball convenient sampling which was started with the help of CSP available in that particular village. A total of 100 individual responses were collected through questionnaire along with one focus group discussion with household and one focus group discussion done with $\mathrm{BC}$ agents working there.

\section{Results and Discussion}

Gender Mix - (Male-Female)

Considering methodology and sample distribution as defined, the overall gender mix of actual respondents viz. male and female were found in the ratio of $60: 40$ (Figure 1). 


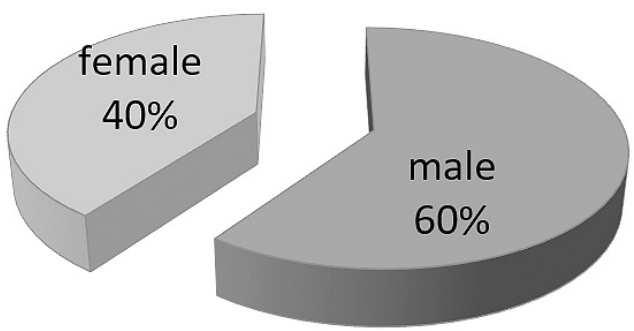

Fig. 1: Gender mix during the survey

\section{Age Group}

Age group between 25-49 years represented maximum sample size which is about $62 \%$, followed by $18-24$ years (18\%), 50-64 years (17\%) and $65-80$ years $(3 \%)$ respectively (Figure 2 ).

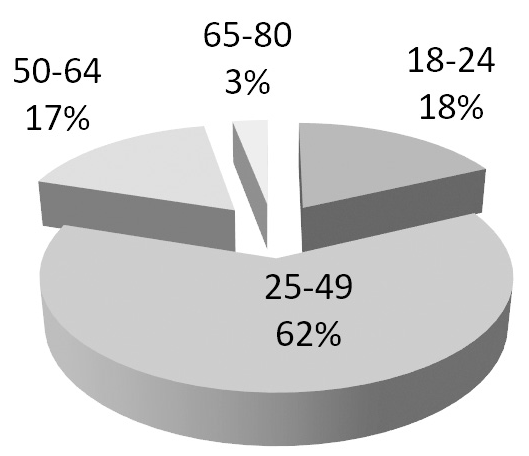

Fig. 2: Age group mix

\section{Education}

People were found from various educational backgrounds, and $34 \%$ of respondents were having an education above secondary level while $13 \%$ people were illiterate (Figure 3).

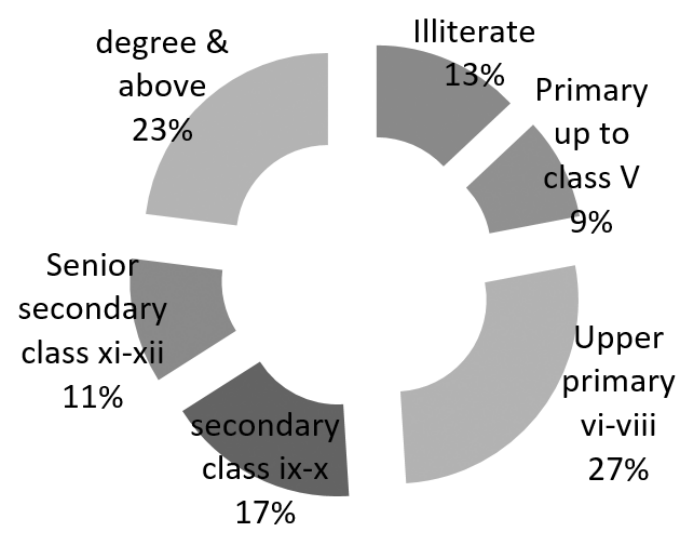

Fig. 3: Education mix

\section{Occupation}

More than a quarter of the respondents were selfemployed (agriculture) followed by a housewife/ homemaker, bank Sakhi, salaried (private) (Figure 4).

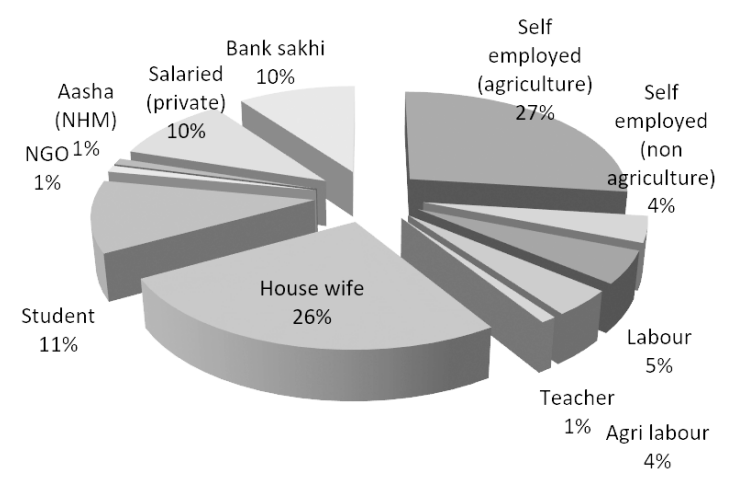

Fig. 4: Occupation of people in the study area

\section{Bank Accounts}

In the last two years, i.e. 2016 onwards, there is a huge increase in the quantum of bank account holders. According to the findex report of 2017, 90\% of people have a bank account in India which was $54 \%$ in the 2014 report $^{3}$. (Kunt et.al., 2018).

About $94 \%$ of persons in the sample had a bank account, but $50 \%$ of them were not in operation, they just opened once, and there is not a single transaction especially if we talk about "Jan Dhan account (Figure 5).

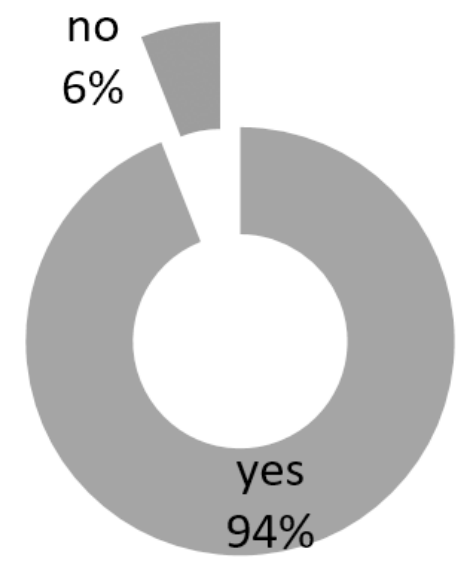

Fig. 5: Persons having bank accounts 
The reason behind not having a bank account was that they didn't have enough money to save in a bank that's why they didn't open the bank account (even the zero balance account). Here we can notice a lack of awareness clearly, and their attitude towards saving was low. They didn't know about the benefits and perks of Pradhan Mantri Jan Dhan Yojna (PMJDY), and that's why they didn't have account till now.

\section{ATM Card}

From the sample of 100 individuals, 94 people had bank accounts, out of that only $32 \%$, i.e. only 30 people had a debit cum ATM card.

\section{Usage of ATM (in Last Three Months)}

About $36 \%$ respondent out of 30 respondents who had ATM cards, didn't use their ATM cards in the previous three months, while $40 \%$ respondents used them between 1-3 times in the last three months. There were some cases of ATM theft in the village after that people have lost faith in ATM card and stop to using them or started blocking their ATM card (Figure 6).

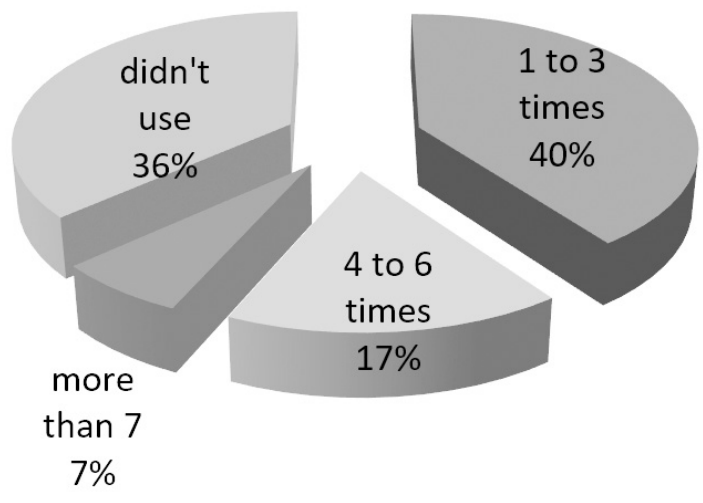

Fig. 6: Usages of ATM in the last three months

Today we are living in the era where people don't have a pucca house, but they do have a mobile phone which might be a feature phone or a smartphone. However, in the villages (under survey), still some people don't have smartphones, the primary reason is not affording these phones due to high prices. Of the $79 \%$ respondents having mobile phones, about $31 \%$ respondents used it for phone calls and messaging while $19 \%$ respondent used for just phone calls as they can't read the message in a mobile. Only $4 \%$ of respondents were found using Internet and banking (via mobile phone).

\section{Internet Users}

From the sample, 79 people had mobile phones, out of which $43 \%$, i.e. 34 people knew how to use the Internet. The majority (57\%) of the people were ignorant about internet usage (Figure 7).

\section{Do you know how to use Internet}

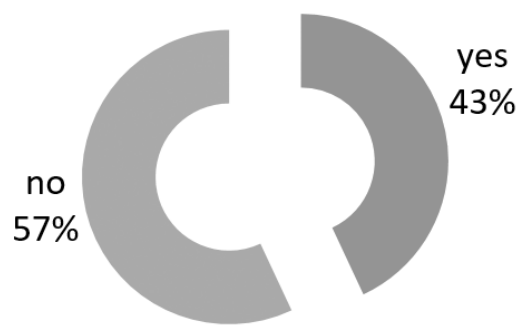

Fig. 7: Use of internet via phone

Those who were using the internet, they were using it mostly for social media, watching a movie, \& for news only. Very few (below $10 \%$ ) were found using for Internet banking/phone banking.

\section{Banking and Digital Channels}

Out of 10 villages visited by the researcher, microATM was present in all the villages while four villages had access to ATM within $2 \mathrm{~km}$ range \& 5 villages had access to Bank branch within $2 \mathrm{~km}$ range. One village near to town (Hasanganj) had access to kiosk banking, merchant POSs, ATM and Bank branch, all within $2 \mathrm{~km}$ range (figure 8 ).

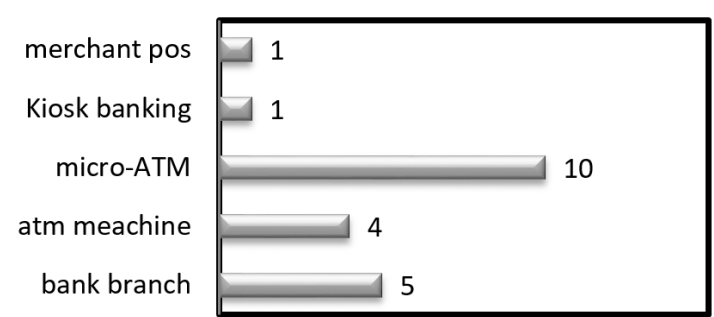

Fig. 8: Number of the villages having digital channels available

About $64 \%$ of people were found currently using any digital device; most of them were using m-ATM as this is available in every village where research was conducted (Figure 9). 


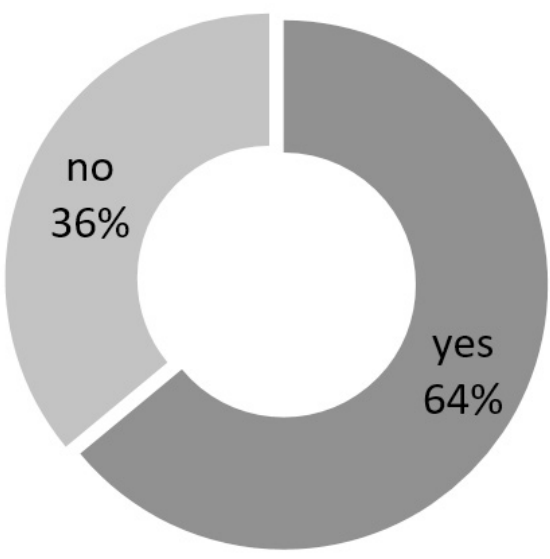

Fig. 9: Number of people using any digital channels

About $60 \%$ of respondents were found using m-ATM very frequently as it was available inside their village and easy to use, no need to fill the form or stand in line for deposit/withdrawal of money from their accounts (Figure 10).

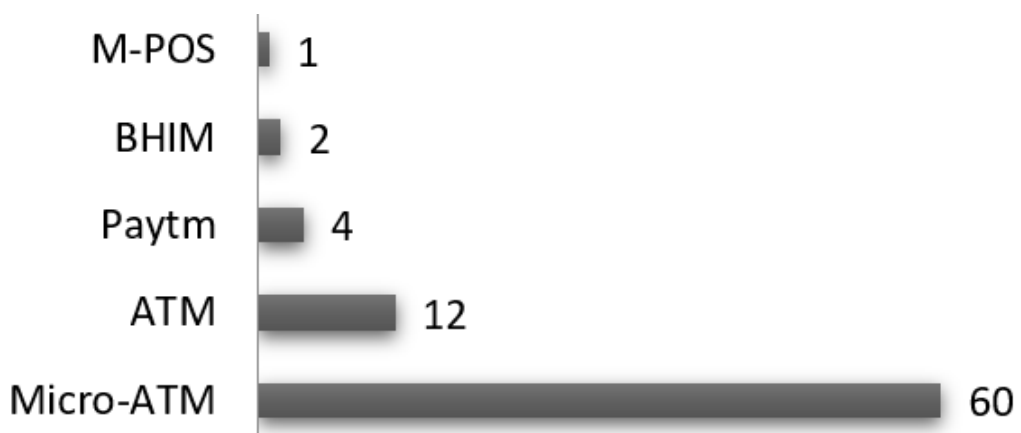

Fig.: 10: Digital medium people frequently used

Awareness of financial products \& financial services It was found that people were aware of many financial products/services, but they were not using them particularly Kisan Credit Cards, insurance, pension post office saving. Some of the products, they are still unaware like a credit card, Rupay debit card and overdraft facilities as not a single person had used a credit card and overdraft facilities provided by banks (Figure 11).

\section{Awareness of Various Digital Channels}

The awareness about ATM and m-ATM was found very good (about 95- 96\%). Among other digital payment channels, there was an awareness about Paytm only, as $49 \%$ of people know about it. When we talked about other channels, lack of awareness was found among them as the people didn't hear about them. Only $13 \%$ of people hear about BHIM, $2 \%$ people hear about Bharat QR and 9\% about USSD (Figure 12).

According to Reserve Bank of India report the total currency in circulation 13,352.3 billion in March 2017(Table 2$)^{4}$. As of February 2018 total currency in circulation 17.82 lakh crore ${ }^{5}$. This volume is quite big as cash to GDP ratio of India is $12 \%$ which is four times higher than that of Brazil, Mexico \& South Africa $^{6}$.

According to another report, globally, the cash in circulation to GDP ratio has ranged from $2.5 \%$ to $8 \%$ whereas in India it has been around $13 \%$ due 
to the predominant usage of cash by a majority of the population ${ }^{7}$. The worldwide growth rates of cash in circulation has varied between $6 \%$ and $13 \%$, with Central \& South America figuring at the top end followed by Africa (12\%), Middle East (11\%), Europe (10\%), Asia (7\%) and finally the UK and Ireland at $6 \%$. Public and private stakeholders have claimed to have developed a few cash-lite (less cash) villages' models in India, but these are sporadic, and learnings are not available in the public domain. There is no prescription (containing strategy and operational guideline) available for transforming a cash-heavy to a cash-lite village economy. Akodra in Gujarat state is a village that is cash-lite now. It is located in Sabarkantha district of north Gujarat, with 220 families and 1145 population. Under the project "Digital Village" ICICI bank developed Akodra as the digital village to mark his $60^{\text {th }}$ anniversary.
The concept of digital Akodra is based on three "Cs": Cashless, Connected and Comprehensive. Cashless: The bank has created a fully cashless eco-system in the village where the shops, Mandi, co-operative society, milk producers in the village can opt for cashless transaction using cards. There are ATM booths if people need cash during an emergency. The villagers don't need to keep cash at home. Connected: The bank has provided high-speed broadband connectivity through the construction of a Wi-Fi tower. The villagers can also do a transaction using mobiles phones. Terminals have been installed to show the prices of agriculture produce. Comprehensive: The village has become comprehensive because digitised school curriculum is introduced; school management software and smart devices have been installed. There are digital boards in Anganwadi ${ }^{8}$.

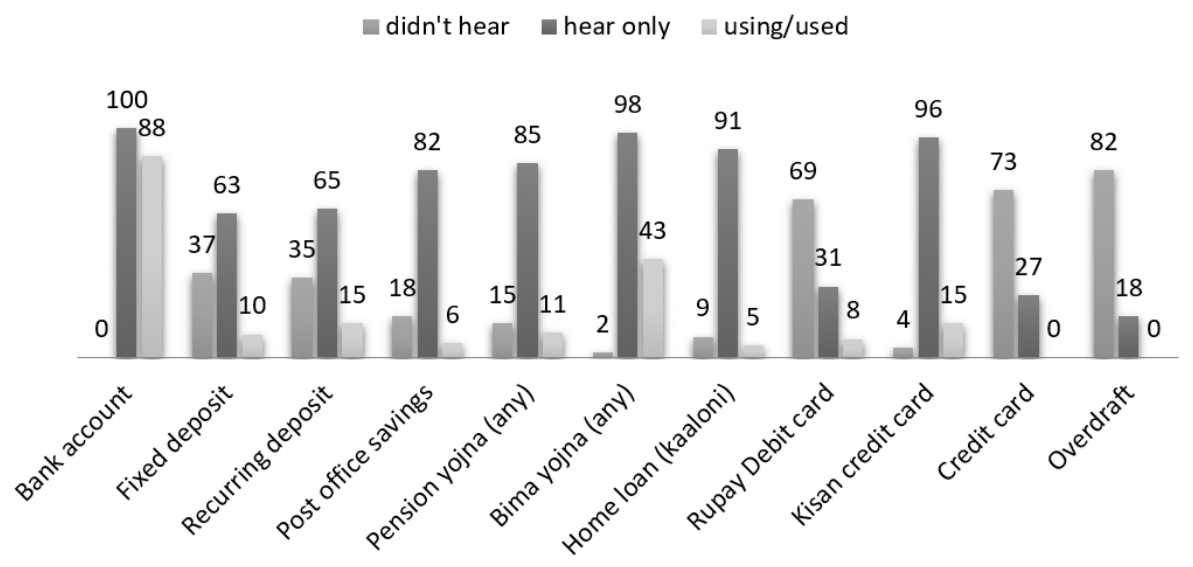

Fig. 11: Awareness of financial products \& services in the area

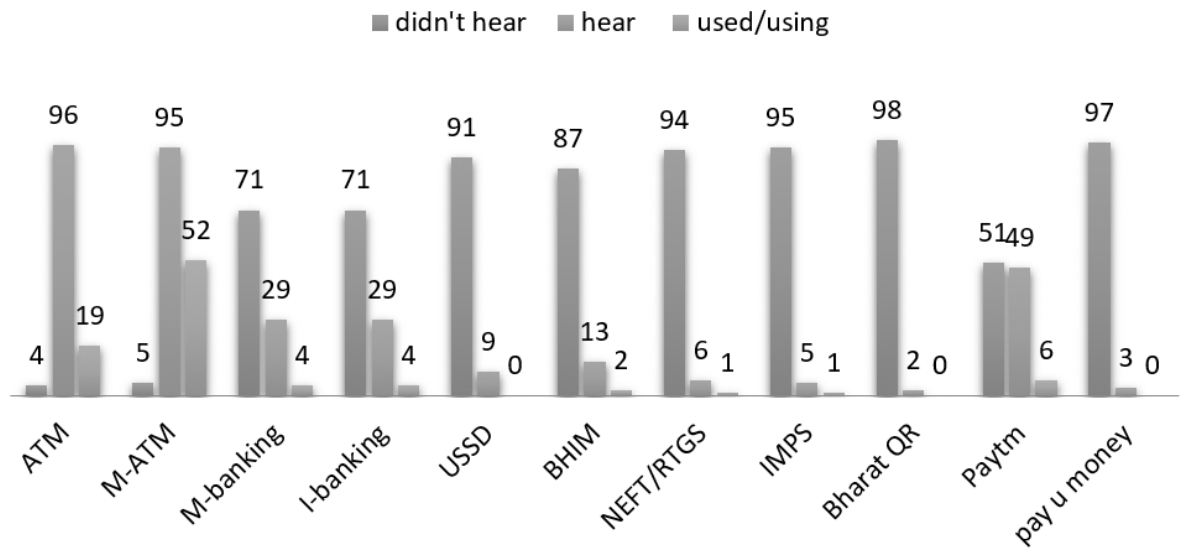

Fig. 12: Awareness of different digital channels 
Table 2: Volume \& value of cash in circulation

\begin{tabular}{lllll}
\hline & March 2015 & March 2016 & March 2017 & Feb 2018 \\
\hline $\begin{array}{l}\text { Banknote in circulation } \\
\text { (Volume in a million pieces) }\end{array}$ & 83,579 & 90,266 & 100,293 & NA \\
$\begin{array}{l}\text { Banknote in circulation } \\
\text { (value in billions) }\end{array}$ & 14,289 & 16,415 & 13,102 & NA \\
$\begin{array}{l}\text { Coins in circulation } \\
\text { (volume in a million pieces) }\end{array}$ & 98,964 & 107,088 & 117,182 & NA \\
$\begin{array}{l}\text { Coins in circulation } \\
\text { (value in billions) }\end{array}$ & 194 & 218 & 250 & NA \\
Total value (billions) & 14,483 & 16,633 & 13,352 & 17,820 \\
\hline
\end{tabular}

Credit card system in India has been explained suitably by Vincent ${ }^{9}$, and according to the author, it was a blessing to both the traders and customers. E-payments and e-banking would be a positive asset for banks, financial institutions, business houses and common citizen of India ${ }^{10}$. Reasons for not attaining full growth potential among card products and remedial measures for growth in this sector has been explained beautifully by Ramakrishna ${ }^{11}$. All above systems have come to India to stay permanently. No central government can reverse the clock now and to curb the menace of black money, increasing income tax base in the country, compliance of tax system by majority population can be ensured by quick adoption of these systems.

During the present study, it was found that the majority of people were doing the transaction through cash only. Only 6\% respondent was found using Paytm or any other medium for recharging their phone or any other services. About $90 \%$ of the respondents didn't even hear about the different digital payments methods like BHIM, Bharat QR, and Paytm. In our study, it was found that $49 \%$ of people have education till eight standards or lower. About $19 \%$ of people don't know how to read the message in mobile phones (out of the people owning mobile phone). In villages, $90 \%$ of villagers have income less than Rs. One lakh, for merchants in the village area, it is costly to manage the POS machines. As there is a high cost to buy them and then monthly charge on POS machine and an additional Marginal discount rate charge of transaction greater than Rs. 2000 per transaction. Following ingredient are needed for converting a cash-heavy village into cash-lite: (a)
Availability of resources such as electricity, mobile network, data connectivity (on operating hours). (b) Mobile phones, POS machine \& data pack at a cheap rate. (c) Awareness among the people, about those digital devices for payments like how to use, benefits while using them.

Electricity was a major issue in rural areas of study. It is found that there was a routine power cut off electricity in particular time and light operated devices cannot be used that time as merchants have to invest extra in batteries, or they have to buy battery operated digital machines for that particular location. Availability of network and connectivity of mobile data in that particular village was found necessary to do any transaction which was internet based. Some limitations were also felt during the study, e.g. due to time constraint, researcher (first author) could survey $7 \%$ villages in Hasanganj block of Unnao district of Uttar Pradesh. Hasanganj block has 156 villages out of which 11 villages were covered by researcher due to the availability of limited time.

\section{Conclusion}

The central government of India need to take some bold steps to convert or encourage cash heavy Indian society to cash-lite, e.g. all the major banks must have a separate counter which will be specifically used for assistance in the cashless transaction $^{12}$. Additional charges on the Cashless transaction should be stopped. Some meaningful privileges must be given to the people who are using Cashless transaction. A large-scale advertising campaign must be launched which will not only promote Cashless transaction but also will provide 
valuable help in using it. Special cash incentive plan must be launched for the consumers as well as people in business for using cashless transaction. This plan can be based on a percentage of the cashless transaction in their total transaction. Central government should lower the import/ custom duty of mobile parts imported from foreign countries so that availability of mobile phones (gadgets) on cheap/ low rate was there and every person in the village can afford to buy.

\section{Acknowledgement}

The first author is thankful to Mr Sachin Kumar CEO \& Co-founder of Samavit Vikas private limited, Noida for providing an opportunity to work on the project titled "To prepare a strategy and operational guideline for developing a cash-lite village model" as a summer intern during April'18 to June'18. I also expressed my deep sense of gratitude to him for his constant guidance and financial support during the project work. I am also thankful to all the people residing in rural areas of Hasanganj Block under Unnao district of Uttar Pradesh for their co-operation in all possible ways to carry out the field work.

\section{References}

1. Gupta, Dinesh Kumar, Demonetization in India 2016 -- Mother Tongue Friendly E-Delivery Banking Channels for Cashless Growth (January 5, 2017). Available at SSRN: https://ssrn.com/abstract=2894129 or http:// dx.doi.org/10.2139/ssrn.2894129

2. Sashidhar, K. (2015). Retrieved 04 09, 2018, from www.livement.com: https://www.livemint. com/Industry/TcmUwOGVb7HIUA5vxDe9ql/ The-lifecycle-and-cost-of-a-banknote.html

3. Kunt A.D., Klapper L, Singer D, Ansar S, Hess J, (2018): The Global Findex Database 2017: Measuring Financial Inclusion and the Fintech Revolution. Washington, DC: World Bank. doi:10.1596/978-1-4648-1259-0

4. RBI. (2011). Retrieved 04 07, 2018, from www.rbi.org.in: https://rbi.org.in/scripts/ AnnualReportPublications.aspx?ld=1005

5. Nayak, G. (2018). Retrieved 04 10, 2018, from www.economictimes.com: https:// economictimes.indiatimes.com/news/ economy/finance/currency-in-circulationalmost-at-pre-demonetisation-levels/ articleshow/63114589.cms

6. Shetty, M. (2015). Retrieved 04 06, 2018, from www.timesofindia.com: https://timesofindia. indiatimes.com/business/india-business/ Indias-love-for-cash-costs-3-5bn-a-year/ articleshow/45934597.cms

7. Chakraborty K C (2014): Currency Management in India: Issues and Challenges. Keynote address of Deputy Governor, Reserve Bank of India at the Banknote Conference 2014, Washington on April 8, 2014.

8. Phukan, R.S. (2015). Retrieved 04 09, 2018, from www.mapsofindia.com: https://www. mapsofindia.com/my-india/government/ akodara-village-indias-first-digital-villagelaunched-by-icici-bank

9. Vincent L (2005): Credit Cards - Modern Payment System. Review of Social Sciences. 6(1):71-76.

10. Jain PM (2006): E.-payments and E- Banking. Indian Banker. 108-113.

11. Ramakrishna R (2006): Card Products in India, Indian Banker. 133-134.

12. Chaudhari T (2017): The critical analysis of cashless transaction. International Journal of Commerce and Management Research. 3(3): 92-94 